\title{
Mobile Application to Practice Fractions through Games for Primary School Children
}

\author{
Sael Flores-Velazquez, Carlos R. Jaimez-González*, Betzabet García-Mendoza \\ Department of Information Technology, Universidad Autónoma Metropolitana, Unidad Cuajimalpa, Mexico
}

Received October 14, 2020; Revised December 18, 2020; Accepted December 30, 2020

\section{Cite This Paper in the following Citation Styles}

(a): [1] Sael Flores-Velazquez, Carlos R. Jaimez-González, Betzabet García-Mendoza , "Mobile Application to Practice Fractions through Games for Primary School Children," Universal Journal of Educational Research, Vol. 9, No. 1, pp. 76 - 84, 2021. DOI: 10.13189/ujer.2021.090109.

(b): Sael Flores-Velazquez, Carlos R. Jaimez-González, Betzabet García-Mendoza (2021). Mobile Application to Practice Fractions through Games for Primary School Children. Universal Journal of Educational Research, 9(1), 76 84. DOI: 10.13189/ujer.2021.090109.

Copyright $@ 2021$ by authors, all rights reserved. Authors agree that this article remains permanently open access under the terms of the Creative Commons Attribution License 4.0 International License

\begin{abstract}
This paper presents a mobile application that supports the learning process of mathematics for fifth grade students, which specifically focuses on the practice of fractions through a series of different games, such as determining if a fraction is less, greater or equals to another fraction; distributing a pizza in fractions; weighing fractions of watermelons; making equivalent fractions; among others. A comparative analysis of existing mobile applications is provided, which is based on some relevant features, such as the types of operations included, the game modes supported, the interactivity of games, the support for two players in the games, the orientation of the games to fractions, the cost of use, the possibility to drag and drop elements in the games of the mobile application, the orientation to fifth grade students, among others. Given that information and communication technologies and ludic are two elements that can provide benefits when incorporated into the teaching and learning processes, this paper also examines different studies that review the impact of mobile devices for designing effective learning experiences in the field of mathematics, the difference between traditional teaching training and the use of electronic devices, and the use of ludic as a component that could benefit the teaching and learning processes through games or entertainment activities.
\end{abstract}

Keywords Primary School Children, Mathematical Fraction, Educational Technology, Interactive Game, Educational Mobile Application

\section{Introduction}

Information and communication technologies can support the learning of almost any knowledge; they can be a source of resources that help to obtain that knowledge. A clear example is online learning, which is a type of training that relies fundamentally on information and communication technologies to create or use distance learning systems and digital resources through the Internet [1].

It is difficult to establish how and when information technologies should be used in the teaching and learning processes. There are not any pedagogical methodologies and techniques that determine the use of information technologies to improve these processes. When using information technologies, you get some advantages, such as the increased interest and motivation of the students. The possibility of interacting with information and having complementary activities enriches the learning process, using digital teaching materials, learning environments, among other resources [2].

Information technologies and ludic are two elements that can provide benefits when incorporated into teaching and learning processes. With information technologies, there is the possibility of complementing or approaching in a new way the teaching and learning processes, through digital resources; while with ludic it is possible to offer a different approach when carrying out the teaching and learning processes through games or entertainment activities, making education look like a fun process.

Regarding information technologies in the teaching of 
mathematics, there are studies that propose constructivism together with the pedagogical practice of mathematics. The same studies suggest that information technologies may be key to modifying teaching methods by adopting new strategies and methods that over time are more effective [3]. A different study makes use of math trail as a learning activity model, which takes advantage of mobile devices for designing effective learning experiences; the study was carried out with primary school students [4].

Another study investigated the difference between the effect of using traditional teaching instruction and using a tablet to teach mathematics for students of first grade of an elementary school in Jordan. The study demonstrated that the use of tablets for studying mathematics was encouraging for teachers and students as part of the learning process; it also showed that in some specific cases students improved their mathematics skills [5].

In relation to ludic, it is considered a component that can benefit the learning process in educational settings; ludic is an element that enables playful learning to be incorporated into educational settings. This method, in addition to developing creativity, offers the benefit of practicing previously learned knowledge, in a more fun way, since the game is accompanied by tension, surprise, joy and satisfaction, among other aspects [6]. There are techniques used through games that reinforce memory, cognitive tasks for learning and better assimilation of content; it should be noted that the game generates greater disposition and interest in the students [7].

A study was carried out with the aim of identifying the effect of mobile gaming in mathematical achievement among students of fourth grade in a primary school. The study had an experimental group, which was taught using educational mobile games; and a control group that was taught by the conventional method. The study concluded that the use of mobile games is an effective practice for providing educational support to the students in mathematics [8].

There are many activities and strategies to include the ludic component in the teaching and learning processes. As an example, there is the case of a study that used different strategies and playful activities, such as simulating everyday activities like shopping, creating activities in the form of riddles and puzzles to address geometry issues, making dynamics with the use of puzzles where students are awarded for solving these correctly. All the strategies of the previous case were successful, for which it was concluded that using the ludic in mathematics can help to change the perspective of the students about the subject being difficult and boring, on the contrary it is possible to generate more interest [9].

The work presented in this paper aims to be a technological tool, specifically an application for mobile devices, that supports the learning process of the mathematics subject that belongs to the fifth grade of primary education in Mexico. The mobile application presented includes different interactive games that specifically serve students to practice fractions topics. The following sections describe some existing mobile applications for practicing mathematics with games, as well as the proposed mobile application with its different games.

\section{Existing Mobile Applications}

The use of technologies to carry out or support the teaching and learning process in education has become popular. In 2006, for example, the Arizona State University teamed up with Google, using what is known as Google apps for education, which consists of software provided by Google for universities; this software ranges from email to web pages, among others, with the aim of improving communication between students and teachers, as well as facilitating access to information [10].

In Mexico, during the first decade of the 20th century, projects of the same nature have been carried out. On one hand there is Enciclomedia, a system that has a platform that provides several resources for primary school teachers to present the supported content in different technological resources such as projectors, computers and electronic whiteboards [11]. Another project developed is Edumóvil, a system whose objective was to provide a series of applications for Palm devices of the personal digital assistant (PDA) type, for supporting different subjects where students presented learning difficulties [12].

In addition to those systems, there are many mobile applications for practicing mathematics with games, through interactive exercises. Google Play Store has some of these mobile applications available for download. This section describes some mobile applications that are similar to the proposed mobile application presented in this paper. The functionality and features of the following applications are described: Teacher of Mathematics [13]; Games of Mathematics [14]; Mathematics vs Undead Game [15]; Mate 5 Challenges [16]; Mathematical fractions [17]; Fraction fraction [18]; and Fractions calculator [19]. A comparative table is also presented at the end of the section, along with an explanation of the relevant features.

\subsection{Teacher of Mathematics}

It is a mobile application [13] in which the student assumes the role of a baby and starts solving mathematical problems, such as simple additions, subtractions, multiplications, and more complex operations such as fractions, square roots, exponentiation, among others. Each game will last until the student misses two answers in a row or when the time runs out. For each correct 
answer, the student will be awarded some points and earn additional rewards such as coins and randomly diamonds. The student will be able to use the coins and diamonds in order for the character to evolve from baby to the following levels: child, school boy, student, and finally, a teacher.

Some of the topics covered in the Teacher of Mathematics mobile application are the following: addition, multiplication, division and subtraction of natural numbers; addition and subtraction of fractions; powers, roots, and operations with parentheses with natural numbers, among others. Figure 1 shows screenshots of two of the games included in this mobile application: the first image shows the addition of numbers, and the second image illustrates the addition of fractions. The number of coins awarded is displayed in the right upper corner of the screen.
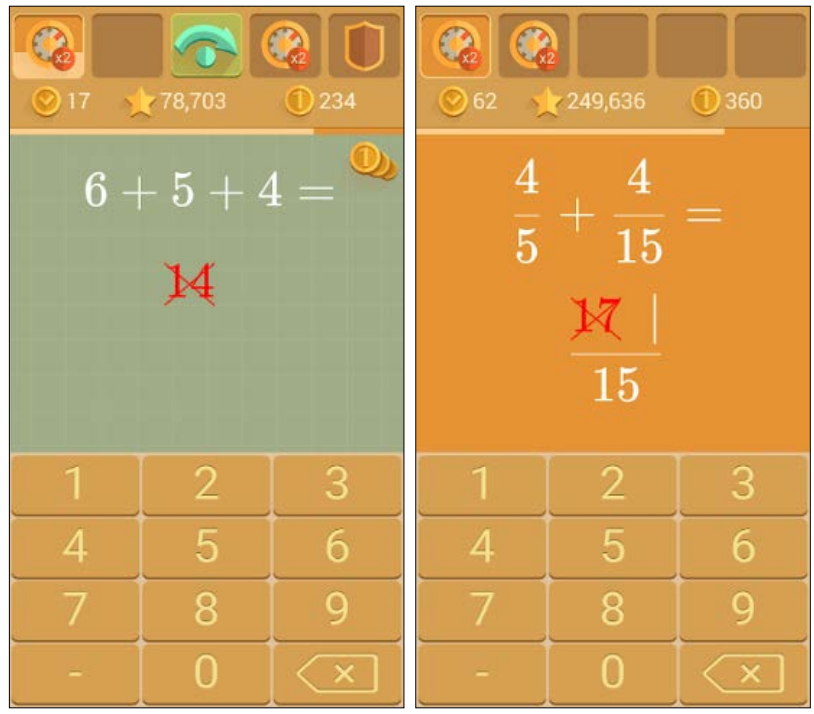

Figure 1. Teacher of Mathematics mobile application

\subsection{Games of Mathematics}

This mobile application [14] includes the basic operations of addition, subtraction, multiplication and division with natural numbers. It does not have levels, but a menu with different games to choose from. Some of the games included are the following.

Block game. The aim of this game is to place blocks on other blocks of the same value, in order to be added forming only one block with the added value, otherwise they will be accumulated on screen. The game ends when the screen is filled with blocks.

Puzzles. This game shows a series of operations with only the result. The student must complete the operations correctly with the values that will be displayed at the bottom of the screen. These operations have to be dragged by the student from the bottom of the screen to the corresponding location, until all operations are completed.

Two-player game. This game is designed for two students to play at the same time. The screen is divided in two parts and an operation is shown on both sides of the screen, as well as the possible responses. Players must answer correctly before the opponent in order to accumulate points and win the game. The winner is the player that reaches the maximum point limit first.

Relate columns. The game consists of a column with operations and another with results. The student has to link correctly the operations on the left side with the corresponding results on the right side. The game ends when all the elements of both columns (operations and results) have been correctly linked.

Figure 2 shows screenshots of two of the games included in this mobile application: the first image shows the block game with blocks in different colors; and the second image illustrates the game to relate columns, where the left column shows the operations and the right column has the results.

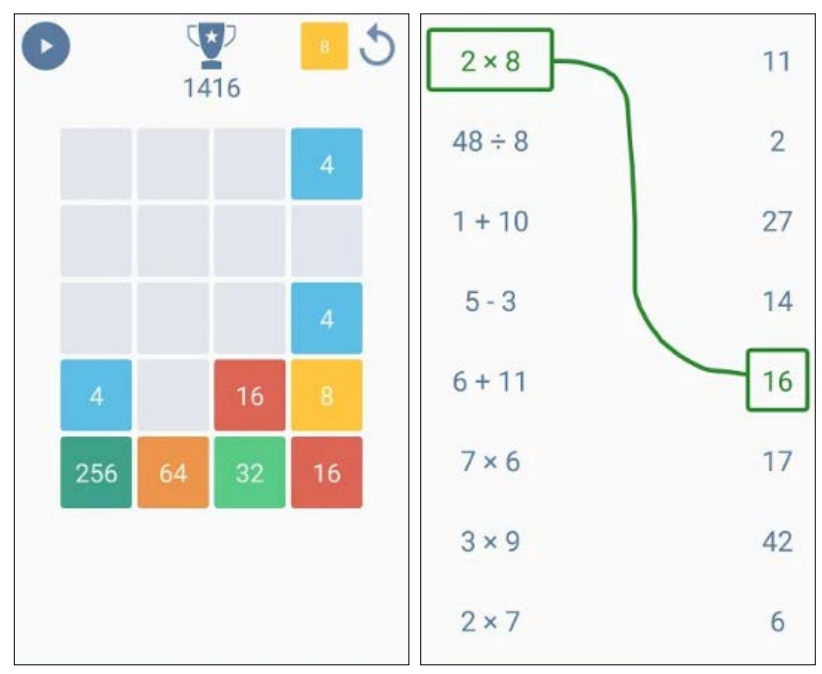

Figure 2. Games of Mathematics mobile application

\subsection{Mathematics vs Undead Game}

It is a mobile application [15] that combines zombies and educational games, aiming mainly at children over the age of six and teenagers. The main character of the game is a math genius who defends himself from numerous zombies using his only weapon, which is the knowledge of math exercises. With each correct answer, the math genius captures evil zombies. The games of this mobile application include the basic mathematics operations at different levels: addition, subtraction, multiplication, and division.

The mobile application also includes mind games involving numbers to test the student's IQ, improve their reflexes and cognitive functions, as well as increase their visual memory. Figure 3 shows a screenshot of one of the games included in this mobile application, where the student has to solve the operation presented by choosing one of the three options provided. 


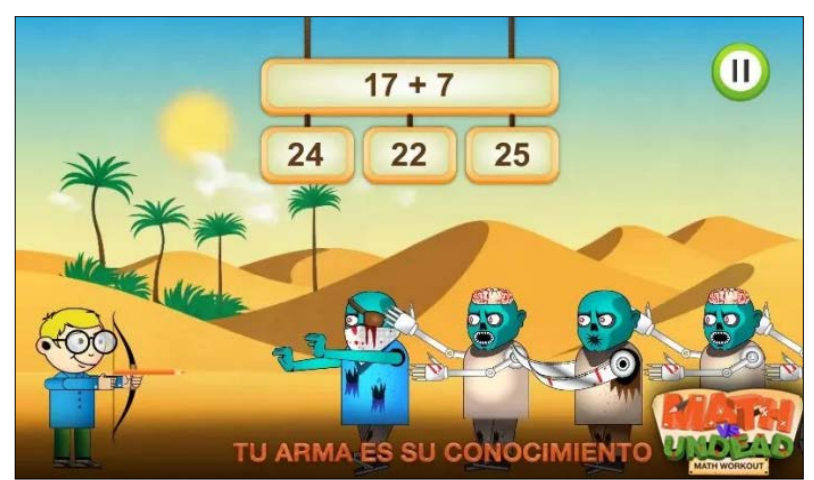

Figure 3. Mathematics vs Undead Game mobile application

\subsection{Mate 5 Challenges}

This mobile application [16] lacks of interactivity, since it only presents the book Mathematical Challenges of the fifth grade of primary school, which is completely solved. Figure 4 shows screenshots of this mobile application: the first image shows a specific unit of the book, where there are several operations (additions and subtractions) with their corresponding results; and the second image shows some other problems and operations with multiple options to choose from, but the correct answer is always indicated with a green tick.

\subsection{Mathematical Fractions}

It is a mobile application [17] that allows the student to learn and practice fractions through visual representations. The mobile application is divided into two parts: learning and practicing.

In the learning part, there is an explanation of the following concepts: 1 ) simple fraction with numerator and denominator, reading of fractions, fraction of a number; 2) representation of mixed numbers and conversion of mixed numbers to improper fractions; 3) definition of equivalent fractions and how to calculate them; 4) comparison of fractions if they have the same or different numerator and denominator; 5) addition of fractions with the same or different denominator; 6) subtraction of fractions with the same or different denominator. The aim of the practicing part is to evaluate the concepts learned in the first part, having the opportunity to select those concepts that the student wants to practice at a certain time.

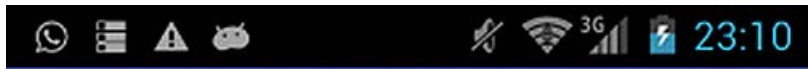

\section{1 dedo=mover 2 dedos=escalar}

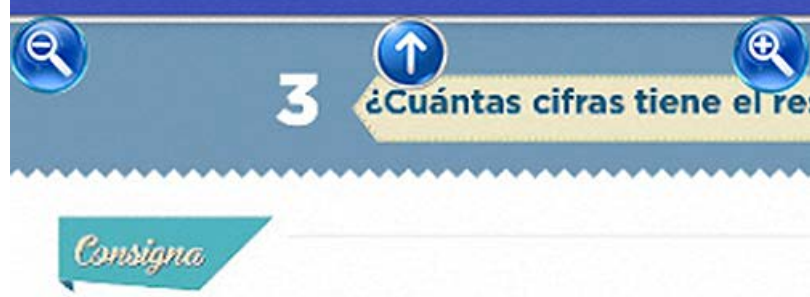

En equipos, determinen el número de cifras del cociente de las siguientes divisiones, sin hacer las operaciones. Argumenten sus resutados.

\begin{tabular}{|r|r|}
\hline \multicolumn{1}{|c|}{ División } & Número de cifras del resultado \\
\hline $837+93=$ & 1 \\
\hline $10500 \div 250=$ & 2 \\
\hline $17625 \div 75=$ & 3 \\
\hline $328320 \div 380=$ & 3 \\
\hline $8599400 \div 950=$ & 4 \\
\hline
\end{tabular}

Ahora, estimen los resultados de las siguientes divisiones: aproximenlos a la decena más cercana, sin realizar las divisiones. Argumenten sus resultados.

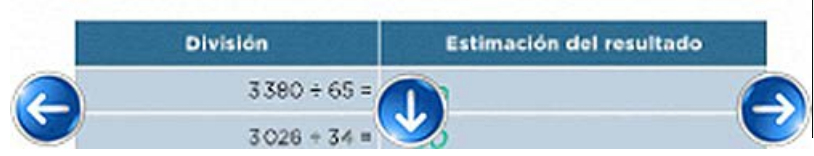

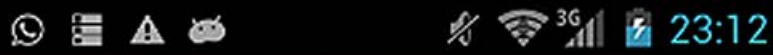

\section{1 dedo=mover 2 dedos=escalar}
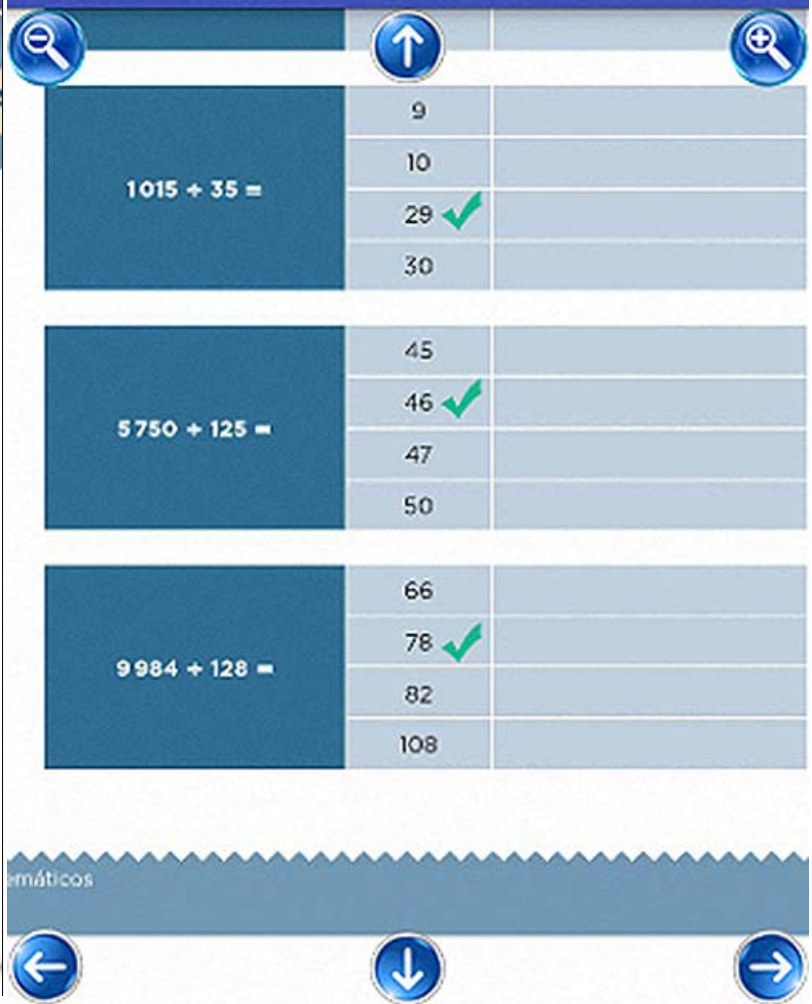

Figure 4. Mate 5 Challenges mobile application 
It should be noted that this mobile application has a multiplayer option to be able to observe the progress of each student independently; it is suitable for children from six to eleven years old; it is possible to play the games without Internet connection; and it is ideal for first to sixth grades of primary education.

Figure 5 shows a screenshot of a game to practice the addition of fractions, which is included in this mobile application; a visual representation of the fraction is presented at the top through rectangles; and some empty boxes have to be filled by the student with the blue numbers located on the right side of the screen.

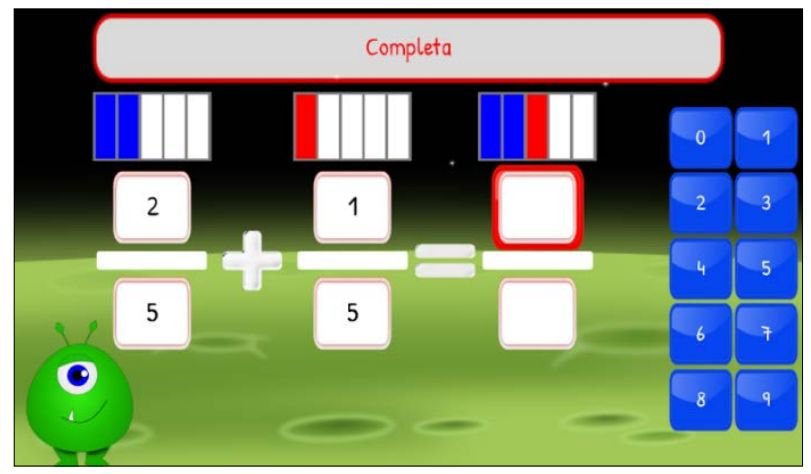

Figure 5. Mathematical fractions mobile application

\subsection{Fraction}

This mobile application [18] is a simple game about addition and subtraction of fractions. Students have to place the fractions in the correct empty boxes, and press the submit button to go to the next operation.

Figure 6 shows a screenshot of the game with an addition of fractions, in which the student has to place the fractions below in the above black boxes, in order to complete the operation correctly. A game includes 50 operations, which can be additions, subtractions or mixed; the number of correct answers is shown at the end of the game.

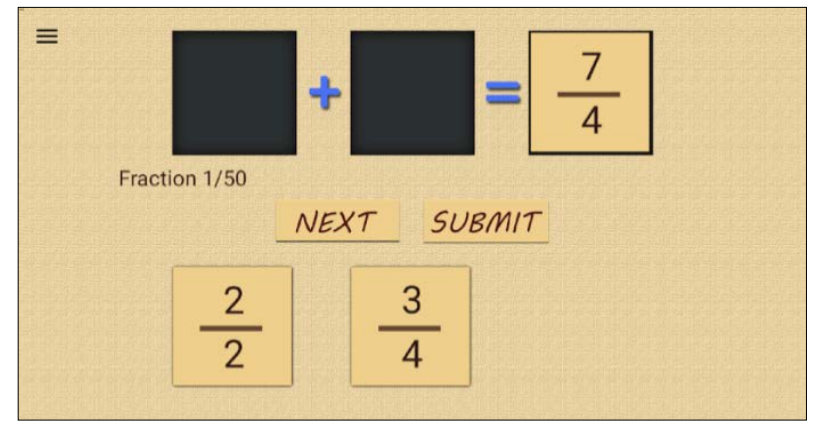

Figure 6. Fraction fraction mobile application

\subsection{Fractions Calculator}

It is a mobile application [19] that contains a module for operations with fractions, such as addition, subtraction, multiplication or division. In the exercises the student has to solve the operation by writing the partial results of the operation. The other module of the mobile application is a fraction calculator. Figure 7 shows the two modules: the first image illustrates the exercise module, where the partial results are written with question marks; and the second image displays the fraction calculator.
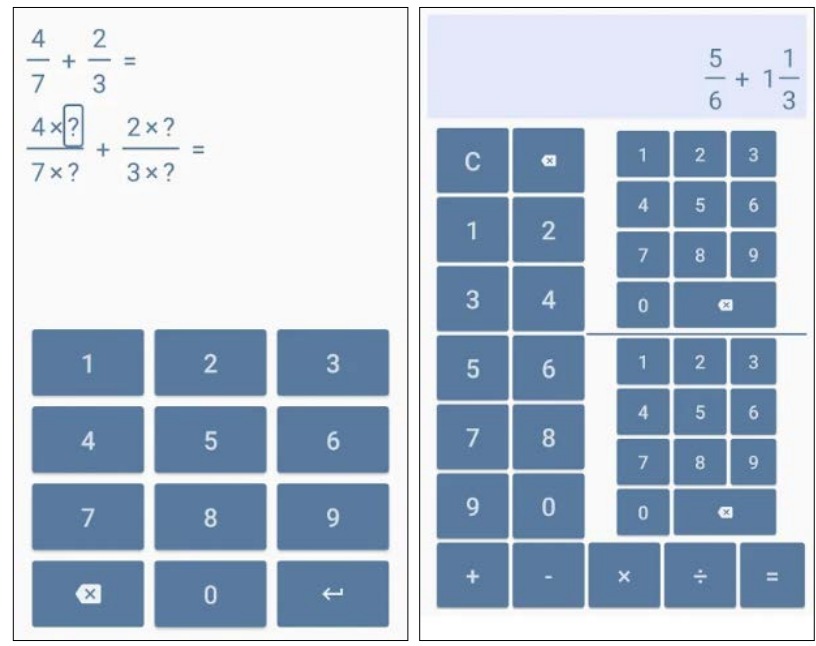

Figure 7. Fractions calculator mobile application

\subsection{Comparison Table}

This section provides an explanation of each of the features found after reviewing the mobile applications previously presented. Table 1 shows a comparison of features of the applications discussed previously and the proposed mobile application. The applications shown in Table 1 are the following: A1) Teacher of Mathematics; A2) Games of Mathematics; A3) Mathematics vs Undead Game; A4) Mate 5 Challenges; A5) Mathematical fractions; A6) Fraction; A7) Fractions calculator; A8) Proposed mobile application. The tick indicates that the application has the feature, while the cross indicates that the application does not have it.

Playful and entertaining. This feature indicates that the mobile application presents its content in a playful and entertaining way through games.

Fifth grade primary. It indicates that the content covered in the mobile application is similar to the content covered in the course of fifth grade of Mathematics.

Focused on fractions. This feature indicates that the content of the mobile application is focused mainly on mathematical fractions.

Operations. It indicates that the content of the mobile application includes operations with mathematical fractions.

Different equivalence types. This feature indicates that the content of the mobile application includes different types of fraction equivalencies.

Free on Play Store. It indicates that the mobile application can be downloaded freely from Google Play 
Store.

Free of payments. It indicates that the mobile application does not contain features or functions for which it is necessary to pay.

Free of ads. This feature indicates that the mobile application does not have any external advertising while using it.

Different game modes. It indicates that the mobile application presents its content in different game modes, such as puzzles, question rounds, exercises, etc.

Interactive. This feature indicates that the mobile application requires interaction from the user, in order to perform some actions.

Drag and drop. It indicates that the mobile application uses drag and drop to carry out exercises or games.

Instructions. This feature indicates that the mobile application has instructions for using it or about the operation of its modules.

Two users. It indicates that the mobile application has game modes where it is possible the interaction of two users.

Table 1. Features of the analyzed applications and the one proposed

\begin{tabular}{|c|c|c|c|c|c|c|c|c|}
\hline Features & $\mathrm{T}$ & $\mathrm{T}$ & $\mathrm{T}$ & $\mathrm{T}$ & $\mathrm{T}$ & $\mathrm{T}$ & $\mathrm{T}$ & $\mathrm{T}$ \\
\hline Playful & $\checkmark$ & $\checkmark$ & $\checkmark$ & $\mathbf{x}$ & $\checkmark$ & $\checkmark$ & $\checkmark$ & $\checkmark$ \\
\hline $\begin{array}{c}\text { Fifth grade } \\
\text { primary }\end{array}$ & $\mathbf{x}$ & $\mathbf{x}$ & $\mathbf{x}$ & $\checkmark$ & $\mathbf{x}$ & $\mathbf{x}$ & $\mathbf{x}$ & $\checkmark$ \\
\hline Focused fractions & $\mathbf{x}$ & $\mathbf{x}$ & $\mathbf{x}$ & $\mathbf{x}$ & $\checkmark$ & $\checkmark$ & $\checkmark$ & $\checkmark$ \\
\hline Operations & $\mathbf{x}$ & $\mathbf{x}$ & $\mathbf{x}$ & $\mathbf{x}$ & $\checkmark$ & $\checkmark$ & $\checkmark$ & $\checkmark$ \\
\hline Equivalence types & $\mathbf{x}$ & $\mathbf{x}$ & $\mathbf{x}$ & $\mathbf{x}$ & $\checkmark$ & $\mathbf{x}$ & $\mathbf{x}$ & $\checkmark$ \\
\hline Free on Play Store & $\checkmark$ & $\checkmark$ & $\checkmark$ & $\checkmark$ & $\checkmark$ & $\checkmark$ & $\checkmark$ & $\checkmark$ \\
\hline Free of payments & $\mathbf{x}$ & $\mathbf{x}$ & $\checkmark$ & $\checkmark$ & $\mathbf{x}$ & $\mathbf{x}$ & $\mathbf{x}$ & $\checkmark$ \\
\hline Free of ads & $\mathbf{x}$ & $\mathbf{x}$ & $\mathbf{x}$ & $\checkmark$ & $\mathbf{x}$ & $\mathbf{x}$ & $\mathbf{x}$ & $\checkmark$ \\
\hline Game modes & $\mathbf{x}$ & $\checkmark$ & $\mathbf{x}$ & $\mathbf{x}$ & $\mathbf{x}$ & $\mathbf{x}$ & $\mathbf{x}$ & $\checkmark$ \\
\hline Interactive & $\checkmark$ & $\checkmark$ & $\checkmark$ & $\mathbf{x}$ & $\checkmark$ & $\checkmark$ & $\checkmark$ & $\checkmark$ \\
\hline Drag and drop & $\mathbf{x}$ & $\checkmark$ & $\mathbf{x}$ & $\mathbf{x}$ & $\mathbf{x}$ & $\checkmark$ & $\mathbf{x}$ & $\checkmark$ \\
\hline Instructions & $\mathbf{x}$ & $\mathbf{x}$ & $\mathbf{x}$ & $\mathbf{x}$ & $\mathbf{x}$ & $\checkmark$ & $\mathbf{x}$ & $\checkmark$ \\
\hline Two users & $\mathbf{x}$ & $\checkmark$ & $\mathbf{x}$ & $\mathbf{x}$ & $\mathbf{x}$ & $\mathbf{x}$ & $\mathbf{x}$ & $\checkmark$ \\
\hline
\end{tabular}

\section{Proposed Mobile Application}

Taking the information from the previous mobile application analysis and the desirable features, a proposal was generated for the development of a mobile application to practice mathematical fractions. The mobile application will be completely free, with no additional charges within the application, it will have no ads, and it will be available for download from the Google Play Store. The mobile application will be playful, interactive, and focused especially to fifth grade students from Mexico.

It is worth mentioning that the aim of the mobile application is to support the practice of fifth grade mathematical fractions and not to replace the teaching process of the subject. For the development of the mobile application it was taken into consideration the contents of the book 5th Grade Mathematical Challenges [20], which is edited by the Ministry of Public Education; it was also considered the key learning factors presented by the Secretary of Basic Education [21] and the comments of some teachers of fifth grade of an elementary school in Mexico; in order to make the content of the application suitable for students. According to these considerations, the following functional requirements were defined.

Access to different game modes. The main modules or games of the mobile application can be accessed from the main interface.

Start Game. Once a game is chosen, the point or time counter must be started in the mobile application. New exercises will be randomly generated. This should be displayed on the screen.

Interaction with interface elements. When starting a new game, the mobile application will allow the student to interact with the interface elements; dragging and dropping items or pressing buttons.

Validation of the exercises. When making the necessary interactions with the interface elements, the responses will be validated by the mobile application to know if the student answered correctly or not.

Display validation. The mobile application has to communicate the student if the answer was correct or incorrect; this communication can be through the screen with a message, sounds and vibrations of the device.

Point count. When starting a new game, the count of the points must be kept, it must be updated after each validation, and it must be shown on the screen of the mobile application.

End of game. Each time a game comes to an end, the mobile application has to give the student a message of the success or time achieved. Along with this information, the mobile application will give the student the option to go to the main page or start a new game in the same game.

Display instructions. For each game, the mobile application will allow to access the corresponding instructions for use.

Navigation within the application. From the main view it will be possible to get to all the modules of the mobile application, and at the same time it will be possible to navigate again to the main page from any point; without closing the mobile application or restarting it.

Once the functional requirements were defined, the following interface model was proposed, which shows some preliminary interface prototypes of the games that the mobile application contains. The prototypes were created with NinjaMock [22]. The mobile application has six modules and each module represents a game: "less, greater or equal", "watermelons and fractions", "distribute the pizza", "1 vs 1", "operations”, and "memory game of fractions". 
The prototype contains screenshots that show the appearance and operation of the mobile application. The design of this prototype was the base for the final design of the different modules of the mobile application. It is important to mention that this prototype was shown to several fifth grade teachers, who approved the initial proposal of the application and commented on the topics of fractions that could be more useful based on their experience as teachers. Figure 8 contains the layout of the application menu interface; this screen shows the options of the different games within the application; each game is represented with a button with which you can access them.

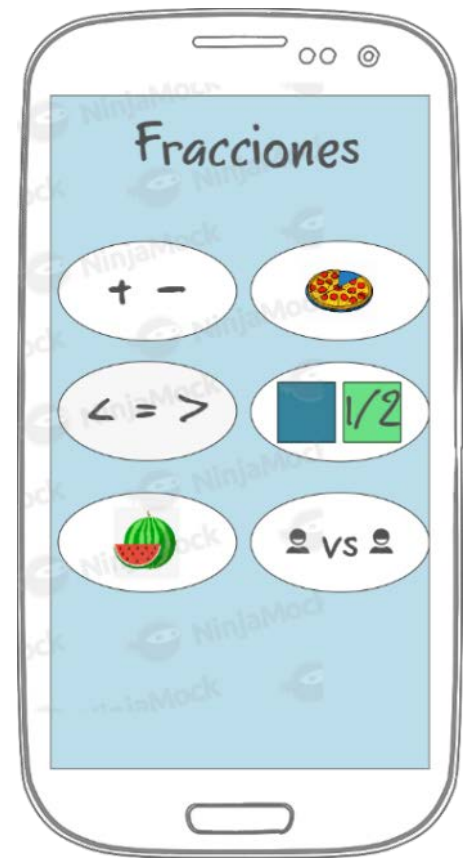

Figure 8. Mobile application with the menu of games

Figure 9 shows the interface of the game "less, greater or equal", in which fractions are presented to compare their values. The student has to drag the correct symbol between the two fractions to answer and at the end, the result of the game is shown. The first image of Figure 9 shows the interface with the two fractions to be compared in the upper part, and the signs of less, greater and equal in the lower part; the second image shows that the student has dragged the sign of greater than, so the answer is incorrect, which is shown with the red cross; finally, the third image shows the points that the student accumulated at the end of the game.

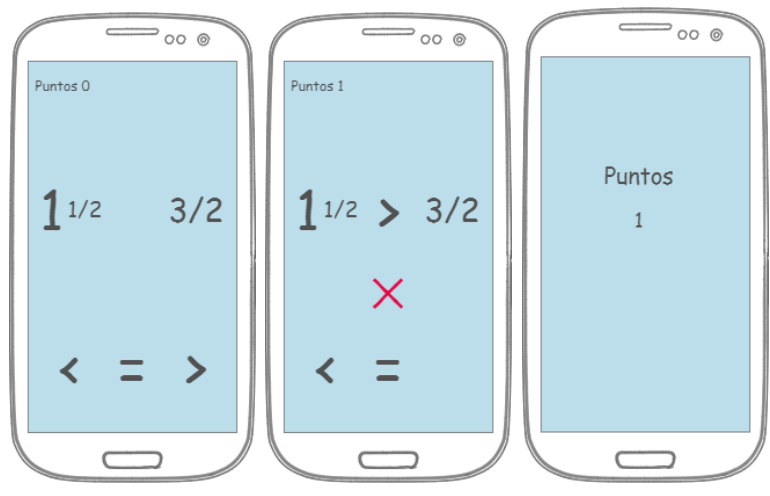

Figure 9. Mobile application with the less, greater or equal game

Figure 10 shows the interface of the game "watermelons and fractions", in which a fractional amount is presented and with the help of the images at the bottom, the equivalent in kilograms must be obtained; the images must be dragged to the central part of the screen and the "Done" button must be pressed to evaluate the answer; at the end of the game the points achieved are shown. The first image in Figure 10 shows the fraction and the images available to drag; in the second image it is shown that the student has dragged a complete watermelon and a quarter, so the answer is correct, which is shown with the green tick; finally, the third image shows the points that the student accumulated at the end of the game.
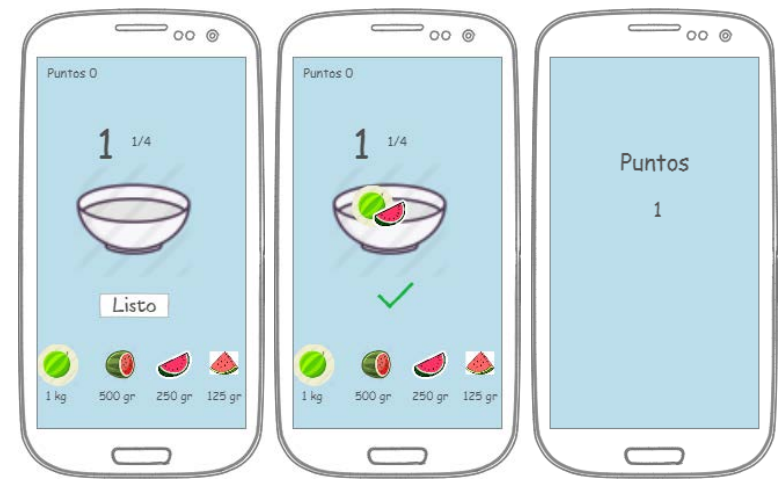

Figure 10. Mobile application with the watermelons game

Figure 11 shows the interface of the game "distribute the pizza", in which a pizza is presented to be distributed, dragging slices to the plates at the bottom, depending on the amount indicated in the fraction. There is a "Done" button to evaluate the answer and at the end of the game the total number of correct answers obtained by the student will be shown. 


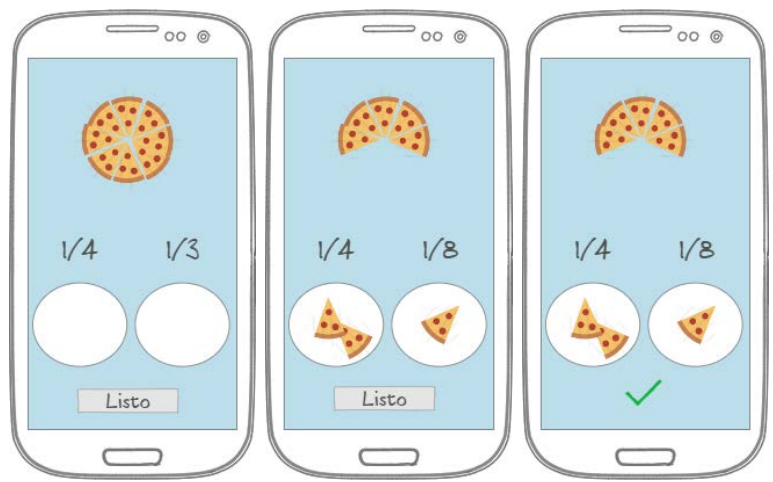

Figure 11. Mobile application with the watermelons game

In the first image of Figure 11, the complete pizza is shown in the upper part, and two fractions in the lower part; the second image shows that the student has dragged two slices of pizza to the first plate, and a slice to the second plate, so the answer is correct, which is shown with the green tick in the third image.

Figure 12 shows the interface of the game "operations", which shows empty spaces that the student must fill, dragging the options shown at the bottom of the screen; there is a stopwatch to check the time in which the exercise is performed. When completing the exercise, the time is shown.

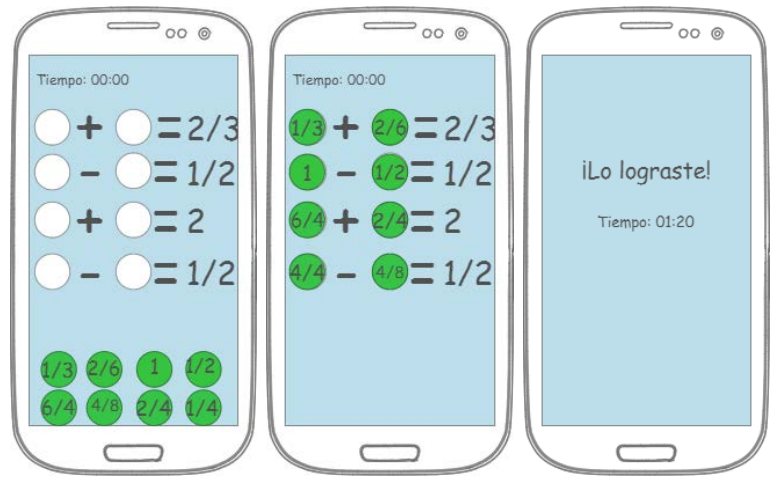

Figure 12. Mobile application with the operations game

In the first image of Figure 12, the empty circles for the fractions are shown with their corresponding results (two additions and two subtractions), and some green circles with fractions are displayed at the bottom; the second image illustrates that the student has dragged the green circles with fractions, and dropped them in the empty circles above; finally, the third image displays a message that indicates that the student completed the game of operations in a time of one minute and 20 seconds.

Figure 13 shows the interface of the game "1 vs 1 ", where the screen is horizontally divided in two to show one question and four possible answers to two users at the same time. Users must answer before their opponent to maintain their lives; when a user loses all his lives, the game will end and the winning user will be shown.

In the first image of Figure 13, the divided screen is presented with an addition of fractions, four buttons with possible answers and hearts that represent the lives of the players; the second image illustrates that the player at the bottom answered correctly, so a green tick is displayed and a heart is removed from the opponent; finally, the third image shows when the top player loses all his hearts, the game ends, and a message is displayed for the winning player.

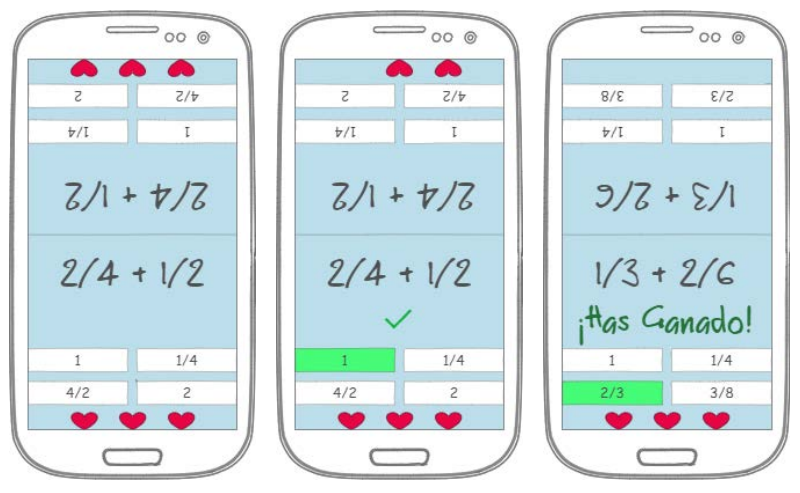

Figure 13. Mobile application with the 1 vs 1 game

\section{Conclusions and Future Work}

This paper presented a mobile application to practice fractions through a series of games, which is intended for fifth grade students. The games included in the mobile application allow students to determine if a fraction is less, greater or equals to another fraction; identifying fractions by distributing slices of pizza; addition of fractions by weighing fractions of watermelons; determining equivalent fractions; among others. The games were described and some interface prototypes were shown.

It was carried out a comparative analysis of seven existing mobile applications to practice mathematics topics. The most relevant features were highlighted, such as the types of operations included, the game modes supported, the interactivity of games, the support for two players, the orientation to fractions, the cost of use, the possibility to drag and drop elements, the orientation to fifth grade students, among others.

Further work is needed to complete the development of the mobile application with its six games. The mobile application will be evaluated by teachers and students in four aspects: functionality, usability, design and didactic features. It is also planned to publish the mobile application in Google Play Store in order to be used freely by teachers and students.

Finally, it should be noticed that the mobile application presented in this paper is part of a set of web and mobile applications that are under development, which aim to support the teaching and learning processes of different subjects of primary education. These applications include a web platform to create memory games for educational purposes [23], and a mobile application to support the teaching of reading and writing of Spanish [24]. 


\section{REFERENCES}

[1] J. Cabero. Bases pedagógicas del e-learning. Universities and Knowledge Society Journal, Vol. 3, No. 1, pp. 1-11, 2006.

[2] C. Ferro, A. I. Martínez, M. Otero, M. Ventajas del uso de las TICs en el proceso de enseñanza-aprendizaje desde la óptica de los docentes universitarios españoles. Revista Electrónica de Tecnología Educativa (Edutec), No. 29, pp. 1-12, 2009. https://doi.org/10.21556/edutec.2009.29.451

[3] S. Castillo. Pedagogical proposal based on constructivism for the optimal use of ICT in the teaching and learning of mathematics. Revista latinoamericana de investigación en matemática educativa, Vol. 11, No. 2, pp. 171-194, 2008.

[4] G. Fessakis, P. Karta, K. Kozas. Designing Math Trails for Enhanced by Mobile Learning Realistic Mathematics Education in Primary Education. International Journal of Engineering Pedagogy, Vol. 8, No. 2, pp. 49-63, 2018. https://doi.org/10.3991/ijep.v8i2.8131

[5] I. Al-Mashaqbeh. IPad in Elementary School Math Learning Setting. International Journal of Emerging Technologies in Learning, Vol. 11, No. 2, pp. 48-52, 2016. http://doi.org/10.3991/ijet.v11i02.5053

[6] J. Duarte. Ambientes de aprendizaje: Una aproximación conceptual. Estudios Pedagógicos, Vol. 29, pp. 97-113, 2003.

[7] G. Sánchez. Las estrategias de aprendizaje a través del componente lúdico. Revista de Didáctica de Español Lengua Extranjera, Vol. 11, pp. 1-68, 2010.

[8] M. Al Khateeb. Effect of Mobile Gaming on Mathematical Achievement among 4th Graders. International Journal of Emerging Technologies in Learning, Vol. 14, No. 7, pp. 4-17, 2019. https://doi.org/10.3991/ijet.v14i07.10315

[9] A. M. Marin, S. E. Mejia. Estrategias lúdicas para la enseñanza de las Matemáticas en el grado quinto de la institución educativa de la Piedad. Fundación Universitaria los Libertadores, Medellín, Colombia, 2015.

[10] K. Barlow, J. Lane. Like technology from an advanced alien culture: Google apps for education at ASU. Proceedings of the 35th annual ACM SIGUCCS Conference, pp. 8-10, Orlando, Florida, USA, 2007. https://doi.org/10.1145/1294 046.1294049

[11] G. Santiago, R. Caballero, D. Gómez, A. Domínguez. El uso didáctico de las TIC en escuelas de educación básica en
México. Revista Latinoamericana de Estudios Educativos, Vol. 43, No. 3, pp. 99-131, 2013.

[12] G. Gerónimo-Castillo, C. Sturm. Edumóvil: El Futuro de la Educación Primaria en México. Portal Educativo de las Américas, pp. 1-12, 2007.

[13] Maestro de matemáticas: juego educativo. Paridae mobile education. Online available from https://play.google.com/st ore/apps/details?id=pl.paridae.app.android.mathmaster

[14] Juegos de matemáticas - Entrenamiento cerebral. Pavel Olegovich Puzzles. Online available fromhttps://play.googl e.com/store/apps/details?id=com.agandeev.mathgames.free

[15] Juego de Matemática vs Undead. Peaksel Games Educational. Online available from https://play.google.com/ store/apps/details?id=com.mathvszombies.mathgame

[16] Ayuda Tarea de Desafíos Mate 5. Pacoelchato Educación. Online available fromhttps://play.google.com/store/apps/de tails?id=com.pacoelchato.apps.ayudaparatutarea

[17] Fracciones Matemáticas Gratis. Aprende y practica fracciones. Boriol Education. Online available from https://play.google.com/store/apps/details?id=boriol.fractio ns.onelite

[18] Fraction Fraction. A puzzle game about fractions. Computational Lab. Online available fromhttps://play.goog le.com/store/apps/details?id=com.priantos.fractionfraction

[19] Fracciones. Entrenamiento y Fracciones Calculadora. Pavel Olegovich Puzzles. Online available fromhttps://play.googl e.com/store/apps/details?id=com.apodev.fractions.free

[20] Secretaría de Educación Pública. Desafíos Matemáticos Quinto grado. Online available from https://drive.google.co m/file/d/1flR-yoIxGkU_yg5MOWkd2CIVdfQ334v6/view

[21] Secretaría de Educación Pública. Aprendizajes clave. Online available from http://www.aprendizajesclave.sep.gob.mx/pr im-ae-pensamiento-mate5.html

[22] NinjaMock. Online wireframe and mockup tool. Online available from https://ninjamock.com/

[23] L. Hernández-Rivera, C. R. Jaimez-González, B. García-Mendoza. Web Platform to Create Memory Games for Educational Purposes. Universal Journal of Educational Research, Vol. 8, No. 12, pp. 6498-6508, 2020. https://doi.org/10.13189/ujer.2020.081215

[24] E. Hernández-Campos, C. R. Jaimez-González, B. García-Mendoza. Interactive Mobile Applications to Support the Teaching of Reading and Writing of Spanish for Children in Primary Education. International Journal of Interactive Mobile Technologies (iJIM), Vol. 14, No. 14, pp. 64-79, 2020. https://doi.org/10.3991/ijim.v14i14.14925 